\title{
EL LAICO Y EL LAICISMO EN SUS FUENTES CRISTIANAS
}

\author{
GODENZI ALEGRE, Jorge Luis ${ }^{125}$
}

La melodramática y exitosa actriz Susan Sarandon, en el festival de cine de Hampton contó que le había enviado al emérito Papa Benedicto XVI una copia del libro "Pena de muerte" que inspiró la película que protagonizara junto a Sean Penn en 1995 y que merecidamente le permitió obtener un Oscar. El entrevistador en ese momento le preguntó si se refería al actual Papa y ella respondió: "No, al último. No a este nazi que tenemos ahora".

Aquel aspaviento histriónico en calificar al Papa Benedicto XVI de nazi da cuenta del sentimiento anti jerárquico que muchos consideran como una incuestionable demostración del laicismo militante que de una manera imparable viene extendiéndose en el mundo católico.

Precisamente ha sido esa tumultuaria ola de "procesión laica" lo que me impulsa a pergeñar, en este ensayículo, la propuesta de que tanto el laico como el laicismo son nociones circunscritas estrictamente al ámbito cristiano, que merecerían ser rediscutidas.

En efecto, el laico es "miembro de aquel pueblo - laos - que es el verdadero Israel de Dios (Gál., 6, 16) la verdadera estirpe electa, el sacerdocio real, la gente santa" de la cual nos habla San Pedro en su primera epístola $(2,9)$. El laico está al margen del cuerpo institucional de la Iglesia, pero es indudablemente miembro del cuerpo místico de Cristo.

El laicismo, por el contrario, es el ideario de vida que promueve hacer obras verdaderamente meritorias dignas de ser anotadas en el Libro de la Vida (Fil., 4,3) siempre que coopere con el apostolado que imparte la doctrina de la Iglesia, en el trabajo genuino de cristianización: Andadura tendiente a fomentar el bien común, la fraternidad, la justicia, la caridad y la consolidación de una moralidad que dignifique a la persona humana.

Traigo a colación esos ideales cristianos de universalidad, dignidad, justicia, caridad, fraternidad y el nutrido acervo histórico porque son los elementos culturales que vigorosamente integran el caudal espiritual del movimiento laicista, que una minoría burguesa ilustrada lo incorporó en sus bitácoras de vida. Ese apostolado marcó un sentido de la vida a los individuos y a las sociedades en un universo ético y de ideales por cumplir.

Esos ideales se erigen desde el reconocimiento y desde la equidad, lo cual implica superar todo tipo de interferencias en desmedro de la libertad. Ese es el camino que afianza la moral laica y no se trata, como algún lector podría conjeturar, de un retorno a una perspectiva en el que solo la religión funde esa moral, sino de una nueva óptica donde inclusive otros cultos puedan contribuir, en el seno de un debate pluralista, a la construcción social de un sentido auténtico de la vida. Este enfoque admite al cristianismo como uno de los elementos que integra al movimiento laicista que venimos a reconocer.

\footnotetext{
${ }^{125}$ Abogado, egresado de la Universidad de San Martín de Porres con Estudios culminados en Maestría y Doctorado en la Universidad de San Martín de Porres, Bachiller en derecho por la USMP. Diplomas de Realidad, Seguridad y Defensa Nacional, curso de especialización en Derecho Civil y Comercial.
} 
Es la cruz, por ejemplo, que trascendiendo su simbología religiosa expresa esa identidad y unos valores de paz y concordia universales. El crucifijo es la manifestación del caudal histórico en el que el cuerpo místico de Cristo compone un capítulo irrenunciable. Por supuesto que no olvidamos que en este contexto, la Iglesia sobresale como gran defensora de una sana y elevada tradición, cuya rica aportación innegablemente se encuentra al servicio de la sociedad.

Así es, la Iglesia tiene "una misión de verdad que cumplir en todo tiempo y circunstancia a favor de una sociedad a medida del hombre, de su dignidad y de su vocación. [...] La fidelidad al hombre exige la fidelidad a la verdad que es la única garantía de libertad (cf. Jn 8,32) y de la posibilidad de un desarrollo humano integral. Por eso la Iglesia la busca, la anuncia incansablemente y la reconoce alli donde se manifieste. Para la Iglesia, esta misión de verdad es irrenunciable" (Enc. Caritas in veritate, 9). Para una sociedad formada mayoritariamente por católicos, cuya cultura ha sido profundamente marcada por el cristianismo resulta algunas veces dramático intentar encontrar la verdad fuera de Jesucristo. Para los cristianos, la Verdad es divina, es el "logos" eterno que tomó expresión humana en Jesucristo que pudo afirmar con objetividad: "Yo soy la verdad" (Jn 14,6).

La convivencia de la Iglesia con su firme adhesión al carácter perenne de la verdad, con el respeto por otras "verdades", o con la verdad de otros, es algo que la misma Iglesia deberá pronto aprender y que el Papa anterior con finura intelectual vino forjando.

Considero que en este respeto dialogante se pueden abrir puertas nuevas para la transmisión de la verdad de la que hoy, por estar confrontado ante la perplejidad de una pavorosa ambivalencia, resulta una exigencia cimentarla desde una motivación religiosa. Por lo demás, la razón occidental sólo ha sido capaz de suscitar violencia exterminadora y vulgaridad comercial, pero no de fundar auténticos valores sociales dignos de tal nombre. De hecho, un país que deja de saber cuál es su propia verdad acaba perdiéndose en el laberinto del tiempo y de la historia, sin valores bien definidos, sin grandes objetivos claramente enunciados.

Habría que apostar decididamente a favor de una salida positiva e incluso saludable a esta encrucijada de tipo político que viene a coincidir, desafortunadamente, con un proceso de descomposición occidental, complejo y delicado en el que todavía - seguro - nos esperan algunas sorpresas. Todas estas consideraciones pueden ayudar significativamente porque lo importante ahora, una vez superada esta situación, es aprovechar la dura experiencia para modificar ciertos comportamientos y rectificar algunas conductas, en especial las relativas a las tentaciones momentáneas que incitan a brindar motivos para hundirnos en los sentidos abismales perdidos dentro de uno mismo.

La impronta de la laicidad, de vena cristiana, que no sólo tiene que ver con la desconfesionalización de la actividad política y en la actitud de vencer a las jerarquías religiosas, sino de acabar con las diversas formas de dominación económica, social y política, mediante los soportes morales de la honradez personal, el respeto a la dignidad humana, la transparencia en la gestión, la moderación en las ganancias y la equidad distributiva, es aquello en la que los laicos y la iglesia se encuentran raigalmente comprometidos. 
"La Iglesia —escribía el Papa Pablo VI- debe ir hacia el diálogo con el mundo en que le toca vivir. La Iglesia se hace palabra; la Iglesia se hace mensaje; la Iglesia se hace coloquio" (Enc. Ecclesiam suam, 34). Así es. El diálogo sin ambages y respetuoso de las partes implicadas en él es una prioridad hoy en el mundo.

Toda referencia moral es imposible de justificar sin una apelación a algún credo religioso por lo que resulta innovador que los fundamentos de la conducta moral del laico se encuentren enraizadas en una antropología mística que otorgue una dimensión particular a la persona en su devenir. Otra vertiente simplemente al laico lo hunde aún más en el abismo, durante algún tiempo se consideró una esperanza realizable que la moral sea esclarecida por la ciencia, pero infortunadamente sucumbió también al proyectar al género humano como "un borrador que las biotecnologías se encargarán de pasarlo en limpio" propugnando, de ese modo, el diseño de cuerpos dóciles, útiles y eficaces para el proyecto de un capitalismo industrial que merced a la biociencia y a la genética puedan hacer posible las utopías que los ingenieros sociales, favorecidos por las tecnologías electrónicas y digitales, controlen por el "biopoder" las almas humanas. Es decir, cosificar intensamente a las personas para vulgarmente someterlas a fines protervos, todo lo cual constituye a la inhumana negación de la jerarquía de la dignidad humana que como todos sabemos tiene como cimiento a la libertad.

Este tiempo de desintegración espiritual y de decadencia intelectual es un reto para el movimiento laicista que a pesar de la tremenda convulsión axiológica que ahora nos aplasta, lo debe de asumir y para ello cuenta con el soporte de la bimilenaria tradición cristiana que como se ha advertido se ve todavía asediada por algunas lecturas y discursos radicales que para comprenderlas mejor y por las implicancias que tienen, estimo imperativo dirigirme al rico núcleo intelectual de Occidente, en sus dimensiones filosóficas y políticas.

Es el paso del tiempo lo que nos permite ganar en perspectiva respecto de cualquier acontecimiento de carácter histórico. Esquemáticamente hasta 1789 la Iglesia católica estableció los fundamentos principales de la cultura moral común, en cuanto a lo esencial definía lo que parecía "bien" o "mal". A grandes rasgos, el orden "temporal" producía relaciones de fuerza y el orden "espiritual" daba origen a la cultura religiosa y moral. Su alianza y en ocasiones su conflicto ha venido jalonado la historia de la civilización.

En esta lógica, el sistema de lo temporal y lo espiritual (encarnado por una iglesia) fue remplazado por una religión civil que legitimó las leyes y sirvió además de fundamento a la propia moral común. La utilidad social de esta nueva religión se fundamentó en la desconfianza e ineficacia que producía el catolicismo en su afán de construir una nueva moral ciudadana. Estos dos factores pueden explicar las tentativas operadas por la revolución francesa cuya moralidad estuvo fuertemente en una base religiosa. Los derechos del hombre y del ciudadano son rápidamente calificados como "nuevo evangelio", la Constitución y la ley son calificadas como "cosas sagradas". En las nuevas ceremonias se yerguen rezos y cantos patrióticos, la prestación de juramentos, fiestas conmemorativas y "panteonizaciones"; los tres colores, los árboles de la libertad, se vuelven objetos de una veneración casi místicas.

Aquella simbolización, recordemos, se transforma en 1793 en tentativas de cultos revolucionarios (culto de la diosa razón, de la diosa libertad, etc.) al que Robespierre busca arroparlo con cultos mejor consensuados como el de la inmortalidad del alma y de la presencia del Ser supremo. Ambos "dogmas" (típicos de la religión católica que tanta odiosidad producía) fueron la garantía de la revolucionaría moral republicana, tal como lo 
atestigua el título mismo de su célebre discurso del 18 floreal, año II: "Sobre las ideas religiosas y morales con los principios republicanos".

El futuro "buen ciudadano" era aquel que amaba los "principios de 1789" puesto que constituía "la moral cívica y el alma misma de la patria". En la década de 1880 se reavivan los elementos de la religión civil nacidos de la Revolución francesa. En 1880 el 14 de julio llega a ser fiesta nacional y La Marsellesa el himno nacional, algunos años más tarde el templo de Santa Genoveva será de nuevo transformado en Panteón para acoger los restos de Víctor Hugo, después de haber sido el destinatario de majestuosos funerales nacionales. Estas propuestas de profunda simbología revolucionaria reanimaron la conciencia viva de los católicos en la búsqueda y diseño de un nuevo fundamento moral.

La revolución francesa, con su famosa trilogía de Libertad, Igualdad y Fraternidad, de indudable abolengo cristiano, aun cuando se aplicaron paradójicamente con el terror, produjo el abandono de lastres ideológicos para profundizar el cambio del individuo y de la sociedad. En ese contexto histórico la laicidad y el cristianismo supieron mantener la línea de la tradición que arrancó de las concepciones aristotélico-tomistas sobre el mundo y la vida; es el laicismo el que introdujo su cuota de inteligencia y sagacidad en la elaboración, aplicación y desarrollo de los derechos civiles y políticos de ese entonces.

La Declaración Universal de los Derechos Humanos, sancionada por las Naciones Unidas en su artículo primero proclama con solemnidad: Todos los seres humanos nacen libres e iguales en dignidad y derechos y dotados como están de razón y de conciencia, deben comportarse fraternalmente los unos con los otros. Nótese como se sigue respetando y apreciando los apostolados del magisterio del laicismo cristianizado, al orientar y trazar el rumbo de una existencia lograda como individuo y como pueblo; es esa moralidad la que queda sacralizada por la cual se consagra el respeto más absoluto a la dignidad humana.

A diferencia de otras religiones que buscan a Dios mirando hacia lo alto para horadar los límites del mundo invisible, el cristianismo es de signo descendente, porque Dios es quien toma la iniciativa de bajar a nuestro valle, al decir del Benemérito Ratzinger. Así nos lo mostró San Agustín, en una de sus sentencias lapidarias: "Dios se hizo hombre para hacernos dioses a nosotros".

No se trata ya entonces de los dogmas de la iglesia, cuyo afán se centra en describir y perfilar al mundo sino de reglamentar el trabajo genuino de cristianización, que es una de las vías que nos permite un pensamiento "del cuerpo de Cristo" (Col, 1, 24). La moral laica tiene un estatuto eclesiológico, es fundamentalmente un establecimiento de la unidad: "Todo es uno, el uno está en el otro, como las tres Personas"; esa moral es la que también se encuentra perfectamente determinada por un pensamiento de la caridad.

Y son precisamente los Estados modernos quienes buscan por todos los medios construir y mantener el monopolio jurídico, cultural e ideológico sobre la sociedad, por lo que no debe sorprendernos que identifiquen a los movimientos laicistas, de cuño cristiano, el enemigo a vencer por ser portadora de cultura, de identidad, caridad y de sentido de trascendencia. La forma de acoso es desterrar al laico del espacio público y exigirle que lleve una vida fragmentada, impregnada de un tosco agnosticismo individualista. 
Es innegable que aquellos que se consideran agnósticos o ateos, traten a sus semejantes con fraterna solidaridad en virtud del genoma común, la identidad de la especie, la cultura de origen, pero niegan estridentemente la pertenencia a un cuerpo místico común. Es quizás por eso que Joseph Ratzinger ha hablado alguna vez de la orfandad del agnóstico.

En una célebre obra de C. S. Lewis, "Cartas del diablo a su sobrino, Screwtape", un diablo veterano y de alcurnia dedica a un diablo segundón y bisoño una serie de consejos que faciliten su misión en la tierra, entre los cuales se halla éste: "Queremos que la Iglesia siga siendo pequeña, no sólo para que los menos hombres posibles aprendan a conocer al Enemigo, sino sobre todo para que quienes se vuelvan contra él se coloquen en ese estado de exaltación enfermiza y de fariseísmo agresivo característicos de una sociedad secreta". Magnífico consejo que recae a los odiadores más sañudos de la jerarquía eclesial que sólo tienen por común denominador su profunda sacrofobia y su irracional aversión al apostolado cristiano.

Antes de culminar este artículo acabo de informarme, por la agencia Reuters, que Joseph Ratzinger ante una reunión interreligiosa, en el que aproximadamente han participado unos 300 líderes religiosos de todo el mundo entre ellos cristianos, judíos, musulmanes, hindúes, zoroastras, taoístas, sintoístas y budistas, ha reconocido "con gran vergüenza" que el cristianismo ha usado la fuerza en su larga historia y que la violencia en nombre de Dios no tiene lugar en el mundo actual.

Este Papa, al que tildan, aquellos que desprecian cuanto ignoran, de nazi, inquisidor e intransigente tiene la doble dimensión intelectual y pastoral que lo emparenta con los padres de la iglesia antigua que supieron interpretar — como Benedicto XVI hace ahora- los signos de su tiempo. Se trata, nada menos que de un Papa filósofo e ilustrado a quien no solo no asusta sino que se deleita en el diálogo franco y abierto, con filósofos, historiadores, científicos e intelectuales en la Academia del conocimiento. 